\title{
Structure and properties of loaded silica contacts during pressure solution: impedance spectroscopy measurements under hydrothermal conditions
}

\author{
R. van Noort $\cdot$ C. J. Spiers $\cdot$ C. J. Peach
}

Received: 6 April 2008/Accepted: 1 March 2011/Published online: 18 March 2011

(c) The Author(s) 2011. This article is published with open access at Springerlink.com

\begin{abstract}
In order to investigate directly the structure and properties of grain boundaries in silicate materials undergoing pressure solution, in situ measurements of these properties are required. We report electrical impedance spectroscopy measurements, performed, under hydrothermal conditions, on individual glass-glass and glass-quartz contacts undergoing pressure solution. Resulting estimates of the average grain boundary diffusivity product $\left(Z=D \delta_{\mathrm{av}} C^{*}\right)$ for silica transport and of the average grain boundary fluid film thickness $\left(\delta_{\text {av }}\right)$ fall in the ranges $6.3 \pm 1.4 \times 10^{-18} \mathrm{~m}^{3} \mathrm{~s}^{-1}$ and $350 \pm$ $210 \mathrm{~nm}$, respectively. However, the average values for $Z$ and $\delta_{\text {av }}$ obtained were likely influenced by cracking and irregular dissolution of the dissolving contact surfaces, rather than representing uniformly wetted grain boundary properties. Post-mortem SEM observations indicate that the contact surfaces were internally rough. Taken together, our data support the notion that during pressure solution of quartz, grain boundary diffusion is rapid, and interface processes (dissolution and precipitation) are more likely to be ratelimiting than diffusion.
\end{abstract}

Keywords Pressure solution - Grain boundary diffusion . Silica · Quartz · Hydrothermal · Impedance spectroscopy

\section{Introduction}

It is well established that the structure and properties of fluid-filled grain boundaries play a key role in controlling

R. van Noort $(\bowtie) \cdot$ C. J. Spiers · C. J. Peach High Pressure and Temperature Laboratory, Department of Earth Sciences, Utrecht University, P.O. Box 80.021, 3508 TA Utrecht, The Netherlands e-mail: vannoort@geo.uu.nl the kinetics of compaction and deformation of wet crustal rock systems by processes such as intergranular pressure solution (e.g., Rutter 1976, 1983; Lehner 1990, 1995). Much useful experimental work has been done on polycrystalline samples of rock-salt (e.g., Spiers et al. 1990; Zubtsov et al. 2004), quartz (e.g., Schutjens 1991; Dewers and Hajash 1995; Niemeijer et al. 2002) and calcite (Zhang et al. 2002; Zhang and Spiers 2005) in an attempt to quantify pressure solution kinetics at the sample scale, and theoretical studies have identified the grain boundary parameters that need to be determined to characterise the process (Lehner 1990, 1995; Shimizu 1995). Of particular importance amongst these grain boundary parameters, and highly controversial for many years, is the question of the effective thickness and diffusivity of wetted grain boundaries, expressed in terms of the grain boundary diffusivity product, defined $Z=D \delta_{\mathrm{av}} C^{*}$, where $D$ is the diffusion coefficient of the dissolved solid in the grain boundary fluid, $\delta_{\mathrm{av}}$ is the average thickness of the grain boundary fluid film and $C^{*}$ is the concentration of solid dissolved in the grain boundary fluid phase in $\mathrm{m}^{3} \mathrm{~m}^{-3}$. This product $Z$ controls the rate of grain boundary diffusion controlled pressure solution in materials with wetted grain boundaries, but is very poorly constrained (e.g., Rutter 1976, 1983; Revil 2001).

The magnitude of $Z$ has, to some extent, been investigated by means of single contact (or bi-crystal) pressure solution rate measurements conducted on halite-glass contacts (Hickman and Evans 1991, 1992, 1995; Schutjens and Spiers 1999; De Meer et al. 2002), halite-clay-glass contacts (Hickman and Evans 1995) and even quartz-quartz (c.f. Hickman and Beeler 1997) or quartz-indenter (Gratier et al. 2006) contacts, with some success under conditions avoiding neck growth (e.g., see Schutjens and Spiers 1999; Visser 1999; Van Noort et al. 2008). However, because of the associated technical challenges, direct in situ probing of 
the structure and diffusive properties of grain boundaries during pressure solution is rare, limiting the extent to which the process is understood at the fundamental level. Nonetheless, several such studies have been carried out on halite. For instance, De Meer et al. (2002) and Van Noort et al. (2006) studied the diffusivity of annular halite-glass contacts by measuring the electrical resistivity of such contacts during pressure solution of the halite. These authors report values for the grain boundary diffusivity product $Z=$ $D \delta_{\text {av }} C^{*}$ of $3 \times 10^{-20}$ to $2 \times 10^{-18} \mathrm{~m}^{3} \mathrm{~s}^{-1}$, at room temperature. They also found an inverse dependence of $Z$ on normal stress and a clear effect on $Z$ of the crystallographic orientation and associated roughness of the dissolving contact. The $Z$ values obtained are about an order of magnitude higher than values derived from pressure solution rate measurements made in experiments on both polycrystalline halite and on single contacts (Spiers et al. 1990; Hickman and Evans 1995; Schutjens and Spiers 1999). In an attempt to independently determine $\delta_{\text {av }}$ and the product $D C$ in $Z$, De Meer et al. (2005) performed Fourier Transform Infrared (FTIR) spectroscopy measurements on grain boundary fluid films developed during pressure solution of a halite crystal pressed against a fluorite crystal. Their findings indicate that the fluid films occupied continuously evolving, rough, non-equilibrium structures-i.e., an island-channel structure. Interestingly, a thicker $(\sim 85-185$ $\mathrm{nm}$ thick) fluid film formed on dissolving (111) planes than on (100) planes $(\sim 40 \mathrm{~nm})$. Furthermore, on the strongly charged (111) plane, at fluid film thicknesses below $200 \mathrm{~nm}$, the water molecules showed increased polymerisation towards an ice-like structure, or "hard water" (Nakashima et al. 2001, 2004). Diffusion through this structured grain boundary fluid was found to be about an order of magnitude slower than in bulk water.

Though not addressing actively dissolving interfaces (i.e., interfaces undergoing active pressure solution), various studies have been conducted using the surface forces apparatus (Israelachvili 1986; Horn et al. 1989; Vigil et al. 1994; Alcantar et al. 2003) to study the properties of thin aqueous films bound between solid surfaces at room temperature. Such studies have provided data on fluid film thicknesses, fluid viscosities and hence diffusion coefficients-through the Stokes-Einstein relation (e.g., Israelachvili 1986; Horn et al. 1989; Vigil et al. 1994). They have shown that thin aqueous films can be maintained in a stressed contact by surface forces such as repulsive electrostatic forces or hydration forces. In the case of silica, a gel-like surface layer of silanol and silicic acid groups may form, and a fluid film can be maintained by steric repulsion and bonding between these surface groups. Significantly, the viscosity of water trapped between silica surfaces in films only a few nanometers thick has been shown to be comparable to bulk water viscosities (Horn et al. 1989).
Recently, Alcantar et al. (2003) used the surface forces apparatus to study interactions between mica surfaces in various electrolyte solutions. At contact normal stresses between 10 and $50 \mathrm{MPa}$ at $21^{\circ} \mathrm{C}$, they found fluid film thicknesses between these silicate surfaces ranging from 0 to $3 \mathrm{~nm}$. From in situ observations of changing fluid film thicknesses, contact areas and contact forces, induced by changing the electrolyte concentration, ion diffusion rates in thin films of $0.3-1.5 \mathrm{~nm}$ thick were found to be reduced compared to bulk water diffusion, but only by a factor of $2-40$ at most. This and the similarly limited decrease in thin film diffusion rates reported recently for grain boundary diffusion in "pressure dissolving" halite (e.g., De Meer et al. 2002, 2005; Van Noort et al. 2006), contrast strongly with the decrease of up to 5 orders of magnitude predicted in early theoretical studies (e.g., Rutter 1976, 1983). Agreement is much better, however, with more recent models in which values for $D$, in fluid films a few nanometers thick, are estimated to be up to 1 or 2 orders of magnitude lower than in bulk water (e.g., Renard et al. 1997; Revil 2001).

Despite the above surface forces studies, and in situ probing work on halite, no in situ data are presently available on grain boundary structure and properties in quartz, calcite or other minerals undergoing active pressure solution, e.g., under hydrothermal conditions. The work reported here was aimed at directly probing the in situ properties and diffusivity of wetted grain boundaries in pressure dissolving silica and/or quartz. To achieve this, a special cell was developed allowing the electrical impedance of a single, annular, pressure dissolving contact between a silica tube and a quartz or silica anvil to be measured, at high temperatures and pressures. Silica glass rather than quartz tubes were used in this first attempt at such a study, as the kinetics of silica dissolution are faster at lower temperatures. Reliable measurements proved difficult to make. However, in the more successful experiments, measured impedances gave composite $Z$ values dependent on the concentrations of various ions present, which in turn, assuming ionic diffusion rates equal to diffusion rates in bulk water, suggested average grain boundary fluid film thicknesses in the range 100-500 nm. Since these values were likely influenced by contact imperfections such as dissolution pits and/or cracks, they probably overestimate active film thicknesses.

\section{Theoretical background}

Principle of the measurement method

In the experiments reported here, impedance spectroscopy was used to investigate the diffusive properties of annular "grain boundaries" formed at silica glass, and silica glass 
$\mathbf{a}$

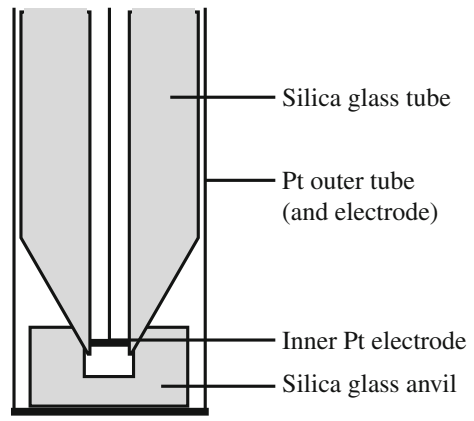

b

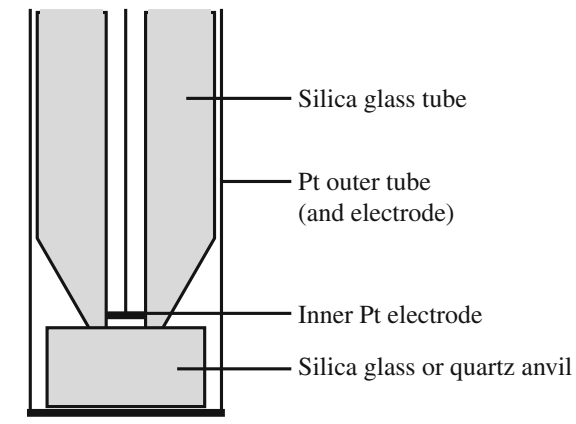

c

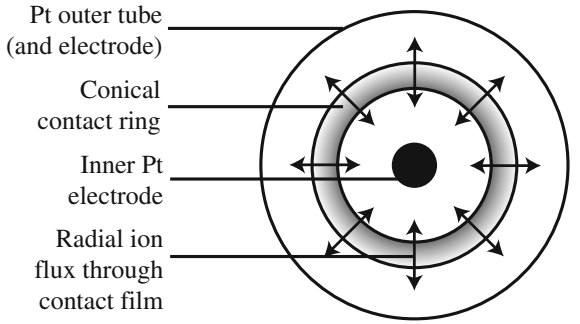

Fig. 1 Schematic drawing of the experimental set-up. a, b Close-ups of the contact between the silica glass tube and a a silica anvil with central hole or $\mathbf{b}$ a quartz/silica anvil without hole. $\mathbf{c}$ Plan view of the contact ring formed during pressure solution of the contact between

against quartz, contacts during pressure solution under hydrothermal conditions. The principle behind these measurements is similar to that employed in the experiments of De Meer et al. (2002) and Van Noort et al. (2006), who investigated the diffusive properties of annular halite-glass and halite-halite contacts undergoing pressure solution at room temperature, by probing the electrical conductivity of the brine-filled contact in combination with in situ microscopic observation of the evolving contact ring.

The geometry of the annular, "pressure dissolving" contact created in our experimental apparatus is illustrated

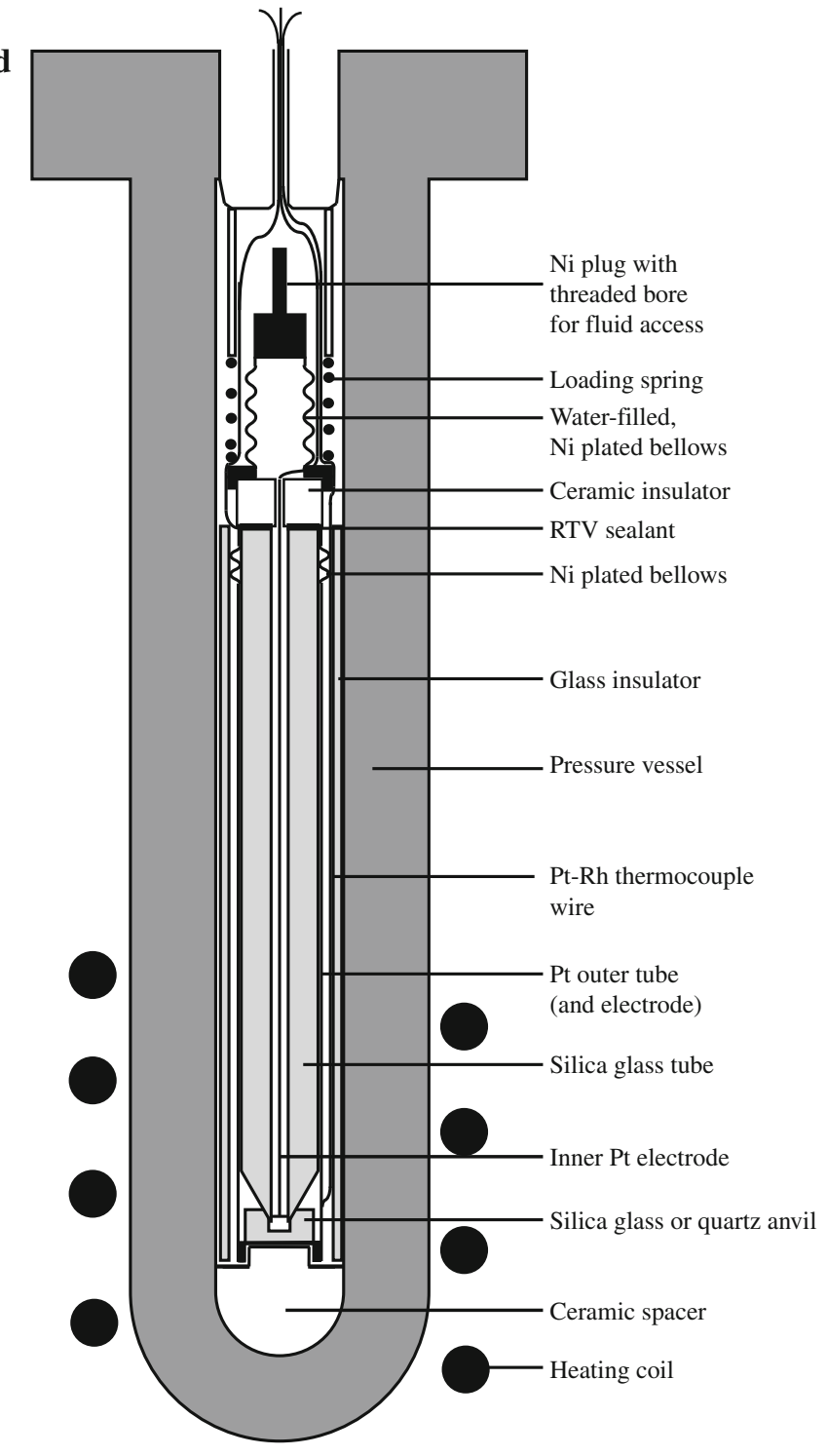

the cone-tipped silica tube and the anvil. d Schematic illustration of the water-filled experimental cell and the cold-seal pressure vessel used to pressurise it

in Fig. 1a-c. The electrical resistance $(\Omega)$ of a ring-shaped contact of this kind is given (De Meer et al. 2002):

$\Omega=\frac{w}{2 \pi r \delta_{\mathrm{av}} \kappa}$

where $r$ is the contact radius $(\mathrm{m}), w$ is the contact width (m) and $\kappa\left(\Omega^{-1} \mathrm{~m}^{-1}\right)$ is the conductivity of the fluid in the grain boundary. The conductivity of a solution of known composition, containing a variety of ionic species $(i)$ can be approximated using $\kappa=\sum \kappa_{i}$, where $\kappa_{i}$, the contribution of ionic species $i$ to the solution conductivity, is given by the Nernst-Einstein equation: 
$\kappa_{i}=\frac{D_{i} C_{i} z_{i}^{2} F^{2}}{R T}$

In this equation, $D_{i}$ is the diffusion coefficient $\left(\mathrm{m}^{2} / \mathrm{s}\right)$ of ionic species $i, C_{i}$ its concentration $\left(\mathrm{mol} / \mathrm{m}^{3}\right), z_{i}$ its ionic charge number, $F$ the Faraday constant $\left(\mathrm{C} \mathrm{mol}^{-1}\right), R$ the gas constant $\left(\mathrm{J} \mathrm{mol}^{-1} \mathrm{~K}^{-1}\right)$ and $T$ absolute temperature (K). Combining Eqs. (1) and (2) with the relation $\kappa=\sum \kappa_{i}$, we obtain the result:

$\delta_{\mathrm{av}} \sum D_{i} C_{i} z_{i}^{2}=\frac{w}{2 \pi r \Omega} \frac{R T}{F^{2}}$

Then, using this result for the various ionic species present in our system (mainly monovalent impurity ions), and knowing $r$ and $w$ from post-experimental observations, a composite $Z$-like value $\left(Z^{c}=\delta_{\text {av }} \sum D_{i} C_{i} z_{i}^{2}\right)$ can be obtained for these ions in the grain boundary fluid, by measuring the contact resistance $\Omega$. This assumes the contact to be overwhelmingly the highest resistance in the cell circuit, which simple tests, performed at room temperature and atmospheric pressure, have shown to be the case. Furthermore, additional effects have to be taken into account, when interpreting electrical conductivity measurements through narrow contacts, such as contributions to the conductivity from conduction through the diffuse layer, Stern layer conduction and from conduction by protons in the hydration layer (e.g., see Revil and Glover 1997, 1998; Revil et al. 1999). These contributions stem mainly from increased concentrations of ions near the surface and can be significant in for instance (micro-)porous materials (Revil et al. 1999; Bolève et al. 2007). In silica systems, the main contributor is conduction through the Stern layer (e.g., Revil and Glover 1998). Logically, these effects are only significant if the conducting pathway (i.e., the contact) is narrow compared to the thickness of the relevant surface layers. By also assuming values for $D_{i}$ equal to the ionic diffusivities in bulk water, and using concentrations obtained as explained below, an apparent value for $\delta_{\text {av }}$ can be estimated, which, if large enough $(>\sim 5 \mathrm{~nm})$ to obviate significant thin film effects on the diffusion coefficient (e.g., Alcantar et al. 2003), would justify the bulk diffusivity assumption. In such a case, we can then use $\delta_{\mathrm{av}}$ to go on to estimate the grain boundary diffusivity product $Z=D \delta_{\mathrm{av}} C^{*}$ for total dissolved silica transport.

Grain boundary fluid composition at experimental conditions

From the above, it is clear that to estimate the conductivity of the grain boundary fluid phase in our experimental setup, and hence to evaluate the product $Z^{c}=\delta_{\mathrm{av}} \sum D_{i} C_{i} z_{i}^{2}$ and estimate the average grain boundary thickness $\delta_{\mathrm{av}}$, it is necessary to know the ionic composition of the grain boundary fluid, i.e., the concentration $C_{i}$ of the dissolved ionic species. Ions are introduced into the fluid by the dissociation of water, the dissolution and dissociation of silica, and the dissolution of any contaminant ions present in the cell at startup. Contaminant ion concentrations were the dominant conducting species (providing $>92 \%$ of $\kappa$ ) and were directly measured after our experiments. The concentrations of other (minor) ionic species $\left(\mathrm{H}^{+}, \mathrm{OH}^{-}\right.$, $\mathrm{H}_{3} \mathrm{SiO}_{4}{ }^{-}, \mathrm{H}_{2} \mathrm{SiO}_{4}{ }^{2-}$ ) and of undissociated, dissolved silica $\left(\mathrm{H}_{4} \mathrm{SiO}_{4}\right.$ monomers, c.f. Volosov et al. 1972; Hiemstra and Van Riemsdijk 1990; Rimstidt 1997; Gunnarsson and Arnórsson (2000) were calculated for our experimental conditions from the literature data shown in Table 1 . In the present study, we combined the dissociation constants for the various silica species, with those of water (see Table 1), to lead to a model for the ionic composition of a saturated silica solution at given pressure and temperature conditions. Figure 2 shows the predicted ionic concentrations at $25-350^{\circ} \mathrm{C}$ and $300 \mathrm{MPa}$. Coupling this model with Eqs. (2) and (3) allowed us to determine the quantity $Z^{c}$ and to estimate $\delta_{\text {av }}$, as described above.

\section{Experimental method}

Impedance cell

The cell we constructed to determine the electrical impedance of single wetted grain boundaries in silicate

Table 1 Reactions and equilibrium constants used to calculate the ionic composition of fluids in our cell at experimental conditions

\begin{tabular}{lll}
\hline Reaction & Equilibrium constant & Reference \\
\hline $\mathrm{H}_{2} \mathrm{O} \Leftrightarrow \mathrm{H}^{+}+\mathrm{OH}^{-}$ & $-\log \left(K_{w}\right)=9.76$ at $300 \mathrm{MPa}$ and $300^{\circ} \mathrm{C}$ & IAPWS (1980) \\
$\mathrm{SiO}_{2}+2 \mathrm{H}_{2} \mathrm{O} \Leftrightarrow \mathrm{H}_{4} \mathrm{SiO}_{4}$ & $-\log \left(K_{w}\right)=9.61$ at $300 \mathrm{MPa}$ and $350^{\circ} \mathrm{C}$ & Gunnarsson and Arnórsson (2000) \\
& $\log \left(K_{\text {am.silica }}\right)=$ & \\
& $-8.476-\frac{485.24}{T}-2.268 \times 10^{-6} T^{2}+3.068 \times \log (T)$ & Volosov et al. (1972) \\
$\mathrm{H}_{4} \mathrm{SiO}_{4} \Leftrightarrow \mathrm{H}_{3} \mathrm{SiO}_{4}^{-}+\mathrm{H}^{+}$ & $-\log \left(K_{1}\right)=\frac{3375.5}{T}-8.0355+0.021748 \times T$ & Volosov et al. (1972) \\
$\mathrm{H}_{3} \mathrm{SiO}_{4}^{-} \Leftrightarrow \mathrm{H}_{2} \mathrm{SiO}_{4}^{2-}+\mathrm{H}^{+}$ & $-\log \left(K_{2}\right)=\frac{4465.2}{T}-8.354+0.021962 \times T$ & \\
\hline
\end{tabular}




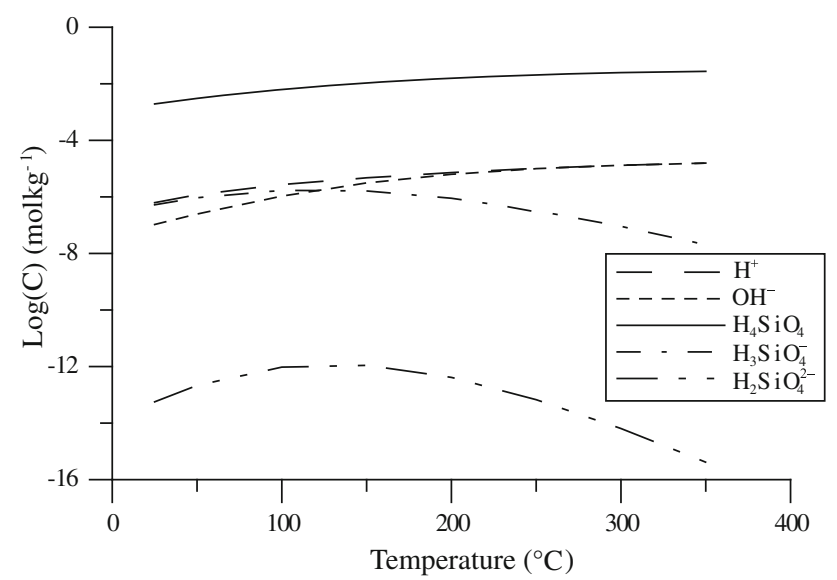

Fig. 2 Predicted concentrations of (ionic) species present in pure silicawater solutions at temperatures between 25 and $300^{\circ} \mathrm{C}$ and pressures of $300 \mathrm{MPa}$, based on solubilities given by Gunnarsson and Arnórsson (2000), silica dissociation constants given by Volosov et al. (1972) and water dissociation constants given by the IAPWS (1980)

materials during pressure solution at hydrothermal conditions is illustrated in Fig. 1d. During operation, the waterfilled cell is placed inside an externally heated, cold-seal pressure vessel, which is pressurised using argon. The electrical impedance of the (pressure dissolving) contact ring, formed between a silica glass tube with conical tip and silica glass or quartz anvil (Fig. 1a-c), is measured using an Impedance/Gain-Phase Analyser.

In detail, the cell consists of an outer tube of platinum, sealed with a welded platinum cup at the lower end and supported at the bottom of the pressure vessel by a ceramic spacer. Spot-welded to the outside of this tube is a platinum-rhodium wire, forming an S-type thermocouple near the tip of the platinum tube. At the top end of the platinum tube, a small nickel bellows is soldered onto the tube, and soldered to this is a nickel-clad, alumina-ceramic insulating block, providing an insulated lead-through for the inner electrode wire. This is further soldered to a second nickel bellows, which compensates for expansion and contraction of fluids in the cell. The second bellows and whole assembly is closed, at the top, with a soldered-in nickel plug containing a threaded bore for priming the cell with fluid. This can be sealed with a small screw that is soldered into place after filling the cell. All soldering was done using tin-silver solder, fluxed with Fluox S.

Inside the cell, the quartz or silica glass anvil, in some experiments with a hole drilled into the centre, is located against the platinum end-cup. The silica glass tube with conical tip is pressed against this anvil, or into the hole, by means of a calibrated spring (placed outside the cell) compressed using spacers of various lengths to provide the desired load on the contact (see Fig. 1d). Note that the spring load determined at room temperature and atmospheric pressure is not necessarily the same as that at experimental conditions, as small differences in (thermal) expansion between the silica glass tube and the (pressurised) vessel might result in a different (likely slightly lower) load. Our estimates suggest a corresponding uncertainty in load of $\sim \pm 3 \mathrm{~N}$. Inside the silica tube, an inner platinum wire electrode, in some experiments with a platinum disc at the tip to increase its surface area, is supported in a silica glass capillary. This inner electrode wire passes through the ceramic insulator and is then soldered to the connection between the nickel-ceramic insulator assembly and the upper bellows. The upper (cool) end of the main silica glass tube was glued onto the aluminaceramic insulator, around the lead-through, using a silicone-based room temperature vulcanising (RTV) sealant, designed for use at high temperatures (up to $260^{\circ} \mathrm{C}$ ) and in humid environments (Comma Instant Gasket). The platinum outer tube (below the ceramic insulator) functioned as the second electrode for impedance measurements. The whole cell was encased in an outer glass tube to insulate it from the wall of the pressure vessel. Outside the cell, the two electrodes and additional thermocouple wire from the cell were connected, via insulated sections, to cone-sealed, high-pressure lead-outs, to provide connections to the measurement apparatus.

The silica glass tubes used in the experiments were cut from stock silica glass tubing. They were ground and handpolished on a lap, in a specially constructed holder to produce a conical tip with apical angle of $60^{\circ}$. Care was taken to ensure that the conical tip was centred on the hole in the tube, so that a contact ring of even width was formed. In early experiments, the silica glass anvils were cut from a silica glass rod. In later experiments, they were cored out of a silica glass plate or optically clear, natural quartz crystal (with top surfaces parallel to the $\{10 \overline{1} 0\}$ form), as the glass rod was found to contain elongated pores parallel to the extrusion axis, which sometimes short-circuited our set-up. All anvils were polished by hand on a lap using P-4000 grade polishing paper. When an anvil with a central hole was used, the top surface of the anvil was ground and polished until the hole had a sharp edge. In one experiment (GC03, see also the list of experiments provided in Table 2), a skirt of platinum foil and a platinum filler piece enveloped the loaded cone-anvil contact at the tip of the silica glass tube, in an attempt to minimise convection and the amount of free fluid around the contact. In addition, the sides of the silica glass tube were painted with platinum paint, with subsequent heat treatment to drive off all volatiles, in an attempt to reduce dissolution and precipitation.

The electrical impedance of the cell was measured between the inner electrode (inside the silica glass tube and 
Table 2 Experimental conditions for the three experiments reported here

\begin{tabular}{llllll}
\hline Exp. No. & Dur. (d) & T $\left({ }^{\circ} \mathrm{C}\right)$ & P $(\mathrm{MPa})$ & Load $(\mathrm{N})$ & Anvil \\
\hline GC01 & 5 & 301 & 300 & 20 & Silica glass from rod, with hole \\
GC02 & 9 & 353 & 300 & 25 & Silica glass from plate, solid \\
GC03 & 27 & 305 & 300 & 16 & Quartz single crystal, solid \\
\hline
\end{tabular}

Between experiments GC01 and GC02, the whole experimental set-up was inverted so that the hot tip of the cell was at the top rather than at the bottom, in an attempt to reduce the driving force for convection

conical tip) and the outer electrode (the platinum tube). Impedance spectroscopy was performed using a Solarton SI1260 Impedance/Gain-Phase Analyser (see also Watanabe and Peach 2002), which, in later experiments (including GC02 and GC03; see Table 2) was connected to a Solartron 1296 Dielectric Interface. Measurements were performed using a sinusoidal excitation voltage, with root mean square amplitude of $500 \mathrm{mV}$. Impedance spectra were measured over a frequency range between $10^{-1}$ and $10^{6} \mathrm{~Hz}$, with $5-10$ points per decade. Using just the Solartron SI1260, impedances could be measured in the range $100 \mathrm{~m} \Omega$ to $10 \mathrm{M} \Omega$ with an accuracy of better than $1 \%$. Using the dielectric interface gives improved accuracy over an increased range of impedances.

Trial experiments with a similar contact geometry as the hydrothermal temperature experiments were performed at room temperature and atmospheric pressure and using a solution of known composition. Varying the contact spacing (i.e., the distance between the anvil and the tube) showed that the resistance of an unloaded contact was $10 x$ as high as the resistance of the open fluid pathway between the electrodes.

\section{Experimental procedure}

The first step in setting up an experiment was the grinding and polishing of the silica glass parts. Next, the inner platinum wire electrode was assembled, coated with platinum black by electrolysis of a solution containing lead acetate and chloroplatinic acid in water to make the surface rough and slid into place in the silica glass capillary and tube. The tube was then glued with RTV against the ceramic insulator in the upper part of the cell. After the RTV had set, the glass or quartz anvil was placed into the bottom of the platinum cell tube, and the conically tipped glass tube was slid into place, along with the top part of the cell (from the lower bellows up), and the nickel lower bellows was soldered onto the platinum tube. The assembled cell was then filled through the small port (threaded bore) located in the nickel top plug. This was achieved by evacuating and then flooding the cell with demineralised and degassed water. After several rinses (to remove any residual flux or other contaminants), the port then was either closed with a tight fitting screw and soldered or temporally sealed to check for changes in fluid resistivity over a few days until the resistance of the cell (after refilling) became stable, and then closed. Once closed, the cell was placed in the Tuttle-type cold-seal vessel, and load was applied to the glass tube-anvil contact via the calibrated spring, which was loaded by closing the vessel. The cold-seal vessel, plus whole assembly, was then mounted into the external heater, connected to the argon gas pressure system and held at room temperature and atmospheric pressure for 1 day to make sure no more changes in cell impedance occurred.

To bring the cell to the desired pressure and temperature conditions, the vessel pressure was first raised to $100 \mathrm{MPa}$ using argon gas. This pressurised the water in the cell to $100 \mathrm{MPa}$ via the action of the bellows. The tube furnace around the tip of the vessel was then switched on, and the rising temperature was monitored. At around $100^{\circ} \mathrm{C}$, the argon and hence cell pressure was raised to $200 \mathrm{MPa}$, and at $\sim 200^{\circ} \mathrm{C}$ it was raised once more to almost $300 \mathrm{MPa}$. The temperature was then further increased to the experimental temperature of 300 or $350^{\circ} \mathrm{C}$, while keeping the pressure constant at $300 \mathrm{MPa}$. Once the cell temperature was stable at the desired value, impedance analyses were performed at regular intervals of 20 or $30 \mathrm{~min}$. Note that during the experiments, only the tips of the pressure vessel and the cell were heated to the indicated temperature, whereas the other end of the vessel was water-cooled, so that a strong temperature gradient existed over the cell.

Experiments were allowed to run for up to 27 days. In terminating an experiment, the furnace was switched off and removed, and compressed air was used to cool the vessel. Once the cell temperature (at the cell tip) had decreased to $200^{\circ} \mathrm{C}$, the argon pressure was decreased to $200 \mathrm{MPa}$. The pressure was then further decreased to $100 \mathrm{MPa}$ at $100^{\circ} \mathrm{C}$ and to atmospheric pressure at room temperature. After removing the cell from the vessel, the port in the nickel plug at the top of the cell was opened to bleed out the fluids, which were retained for chemical analysis by Inductively Coupled Plasma Optical Emission Spectrometry (ICP-OES). The cell was then carefully dismantled. In some cases, the silica glass tube was stuck inside the platinum tube due to local silica precipitation. 
The end-cup was then cut off the platinum tube to save the contact, and the remaining glass tube was removed more forcefully. Optical microscope analysis and Scanning Electron Microscopy (SEM) using Secondary Electron (SE) analysis were used to study the anvil and tube tip after the experiments.

\section{Results and discussion}

In total, 13 experiments were performed while attempting to create a well-sealed silica-silica contact. In most of these experiments, an increase in contact resistance with time was not observed, but a decrease was observed instead. In these tests, the tubes and anvils in all cases showed signs of dissolution and precipitation. Convection, identified through precipitation patterns on the silica glass tube and the large total amounts of dissolved/transported material, also seemed to play a role in most experiments. Cracking was observed in the tube tip after some of the experiments and might have resulted in decreased electrical impedance values by providing additional pathways for conduction. Another possible cause for the decrease in cell resistance observed during the early experiments might have been the release of ions held in the platinum black surface coating on the tube and inner electrode, overprinting any increase in resistance due to the formation of a closed contact. In five of our experiments, an increase in contact resistance was observed. In three of these five experiments, it was possible to preserve the tip of the tube and enough cell fluids for useful study. The results of these three experiments will be presented and discussed here. They are named GC01, GC02 and GC03 for convenience. The experimental details of these three experiments are listed in Table 2.

The starting impedance plots for the three experiments were similar in form and showed a single, slightly depressed semicircular arc (Fig. 3a). The magnitude of the starting impedance (at low frequencies) was very much higher for $\mathrm{GC} 02$, reflecting the lower ionic conductivity, and probably lower contamination of the aqueous solution used in that cell, due to more thorough cleaning prior to filling. The single arcs are indicative of a simple parallel equivalent circuit of capacitive and resistive elements (e.g., Barsoukov and Macdonald 2005), relating to the ionic conductivity of the bulk solution and cell capacitance formed by the platinum electrodes with their associated surface double layers (minimised via platinum black treatment). The impedance of the GC01 and GC03 cells increased during the experimental runs but retained a single arc with increasing depression angle (e.g., see Fig. 3b), indicative of a distribution of capacitance values, presumably produced by the partial development of the dissolution contacts. The final, in phase, impedance at low frequency (i.e., resistance) remained low and similar in magnitude to the starting value of the GC02 experiment (see Fig. 3bfinal arc of GC01 and Fig. 3a-initial arc of GC02).

The experiment $\mathrm{GC} 02$ progressed differently from the other two in that a second arc developed at low frequencies, with more depression than the initial one, which grew to entirely dominate the final impedance spectrum by the end of the experiment (see Fig. 3c). The magnitude of the final arc was an order of magnitude more resistive than at the end of the other two experiments. This second arc represents a second $\mathrm{R}-\mathrm{C}$ network in series with the initial parallel R-C pair of the bulk cell. It is assumed to be due to the restricted ionic transport through the narrow contact region of the dissolution contact, with the effects of double layer capacitance on the contact surfaces and reduced transport of ions by the nearly closed pathways (e.g., see Leroy et al. 2008). A distribution of capacitance and resistance values, suggested by the impedance arc depression, is expected due to the microscopically rough, inhomogeneous, nature of the interface.

\section{Experiment GC01}

In experiment $\mathrm{GC} 01$, the conical tip of the silica glass tube was pressed into a 3-mm central hole machined into the silica glass anvil. A spring load of $\sim 17 \pm 3 \mathrm{~N}$ was used, resulting in a final contact normal stress of about $15 \pm 2 \mathrm{MPa}$. The experiment was run at a temperature of $301{ }^{\circ} \mathrm{C}$ and fluid pressure of $300 \mathrm{MPa}$. The experimental duration was approximately 5 days. Figure 4 a shows the increase in cell resistance with time, as determined by curve fitting. The resistance remained constant at $\sim 15 \mathrm{k} \Omega$ for approximately 2 days, and then increased over the next 3 days to $\sim 150 \mathrm{k} \Omega$, at which point the experiment was ended.

After the experiment, SEM study was performed on the silica glass anvil and tip. Both showed only limited signs of dissolution on their free surfaces. However, a contact ring was clearly visible on the edge of the hole in the glass anvil (see Fig. 4b, c) and around (part of) the conical tip of the glass tube (see Fig. 4d), which we believe to be a "pressure dissolved" contact ring. A composite SEM image of the contact ring formed on the anvil is shown in Fig. 4b. The ring is not of uniform width. This is caused by the fact that the hole in the anvil was slightly off-centre. On the top surface of the anvil, several deep, cylindrical pits, with diameters up to $\sim 300 \mu \mathrm{m}$ have formed due to dissolution, possibly concentrating on voids or impurities (see Fig. 4b). The surface of the contact ring (Fig. 4c) is covered in shallow, concave, reniform depressions, up to $\sim 100 \mu \mathrm{m}$ long and $\sim 50 \mu \mathrm{m}$ wide, and up to a $\sim 5 \mu \mathrm{m}$ deep, with their long axes oriented parallel to the contact 
Fig. 3 Complex impedance plots, showing imaginary impedance $\left(Z^{\prime \prime}\right)$ versus real impedance $\left(Z^{\prime}\right)$. a The first impedance spectrum measurement for each experiment. b The initial and final impedance spectrum measurements of experiment GC01. c The evolution of the impedance spectrum measurements in GC02. Note that a second arc gradually appears at lower frequencies, and then proceeds to dominate the cell impedance. Spikes in the data caused by mains supply interference at $50 \mathrm{~Hz}$ have been removed a

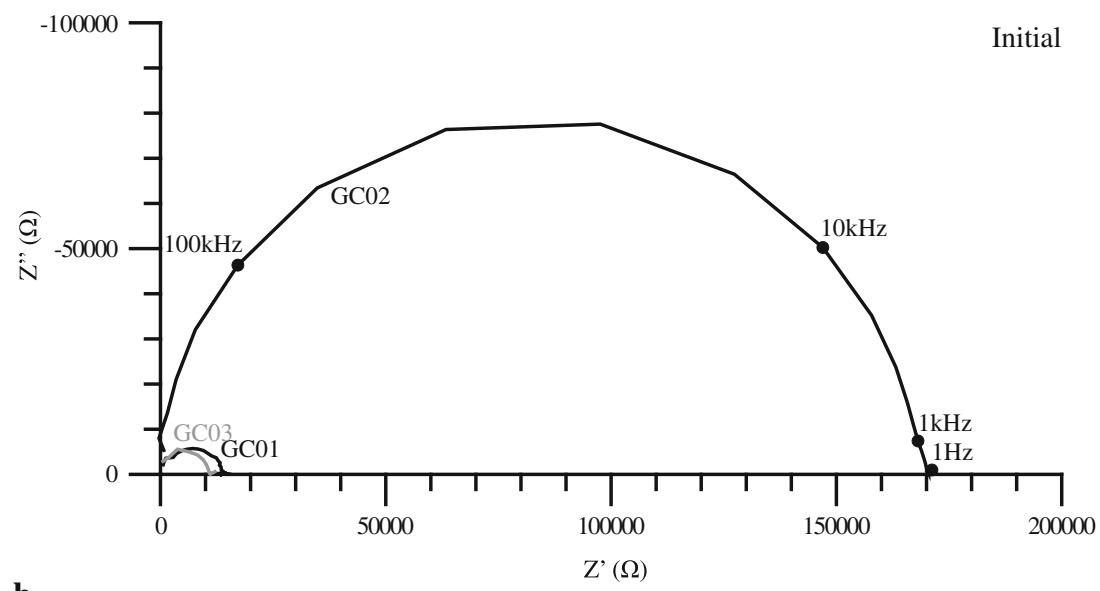

b

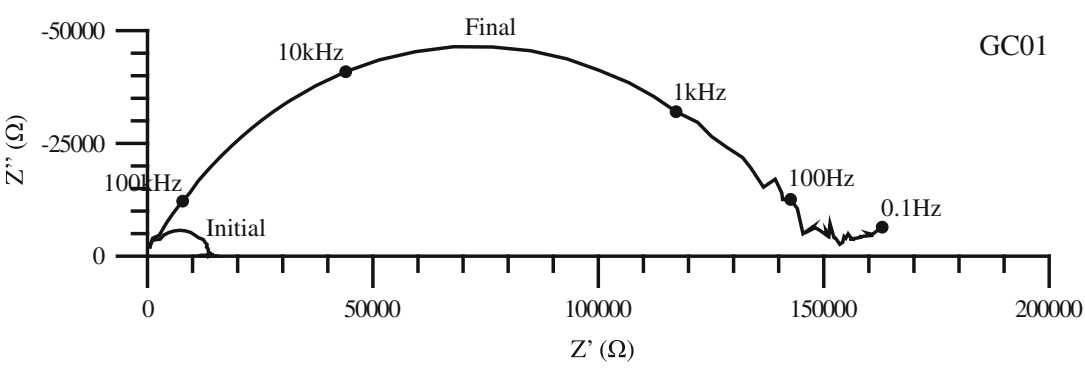

c

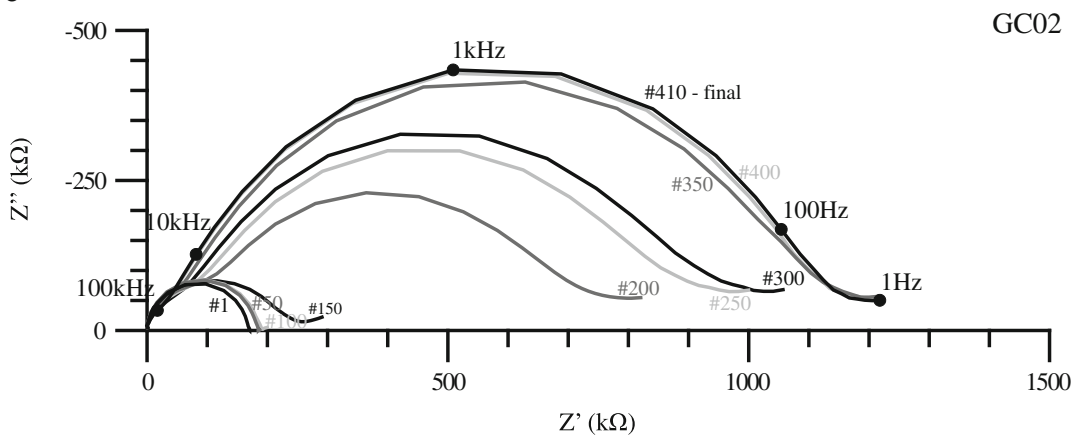

circumference. Unfortunately, one of the (much deeper) dissolution pits observed on the free anvil surface intersects the contact ring (Fig. 4b).

On the free surfaces of the tube tip (Fig. 4d), dissolution resulted in a pitted surface, covered with shallow depressions up to $\sim 100 \times 60 \mu \mathrm{m}$ in size. The small step in the conical surface corresponds to the pressure solution contact with the anvil. On this step, the same texture is found as on the rest of the conical surface. The texture looks very similar to that on the contact ring on the glass anvil. As this texture is found on free surfaces as well as loaded contact surfaces, it is inferred that it mainly formed as a result of dissolution, and not cracking.

From the composite SEM image of the contact ring (Fig. 4b), an estimate can be made of the contact diameter (3.1 mm, assuming an annular contact) and average contact width $(\sim 60 \mu \mathrm{m})$ at the end of the experiment. Inserting these estimates and the final contact resistance value into Eq. (3) then shows that $\delta_{\mathrm{av}} \sum D_{i} C_{i} z_{i}^{2}=2.12 \times$ $10^{-14}$ mols $^{-1}$.

The results of the chemical analysis done on the cell fluids are shown in Table 3. The silica concentration is lower than the solubility at $300^{\circ} \mathrm{C}$, but it is assumed that the fluids were silica-saturated during the experiment and that the remaining silica precipitated during cooling and/or in the time between the experiment and the analysis. Other ionic concentrations are well below room temperature solubilities and are assumed to represent experimental concentrations. The main ionic species present is $\mathrm{Cl}^{-}$. Its concentration is considerably higher than the estimated concentrations of $\mathrm{H}^{+}, \mathrm{OH}^{-}$and charged silica species at $300^{\circ} \mathrm{C}$ and $300 \mathrm{MPa}$. Assuming the presence of a similar concentration of monovalent cations for charge balance (see Table 3), representing all positively charged ions other 
Fig. 4 Results from experiment GC01. a Graph showing the evolution of the contact impedance with time. b A compound SEM SE image of the contact ring formed on the glass anvil. Dissolution pits on the top surface of the anvil are indicated "dp". c Close-up SEM SE image of the contact ring, showing shallow concave depressions. d SEM SE image of the tip of the glass tube used in the experiment. A contact ring can be observed on its surface, indicating the operation of pressure solution
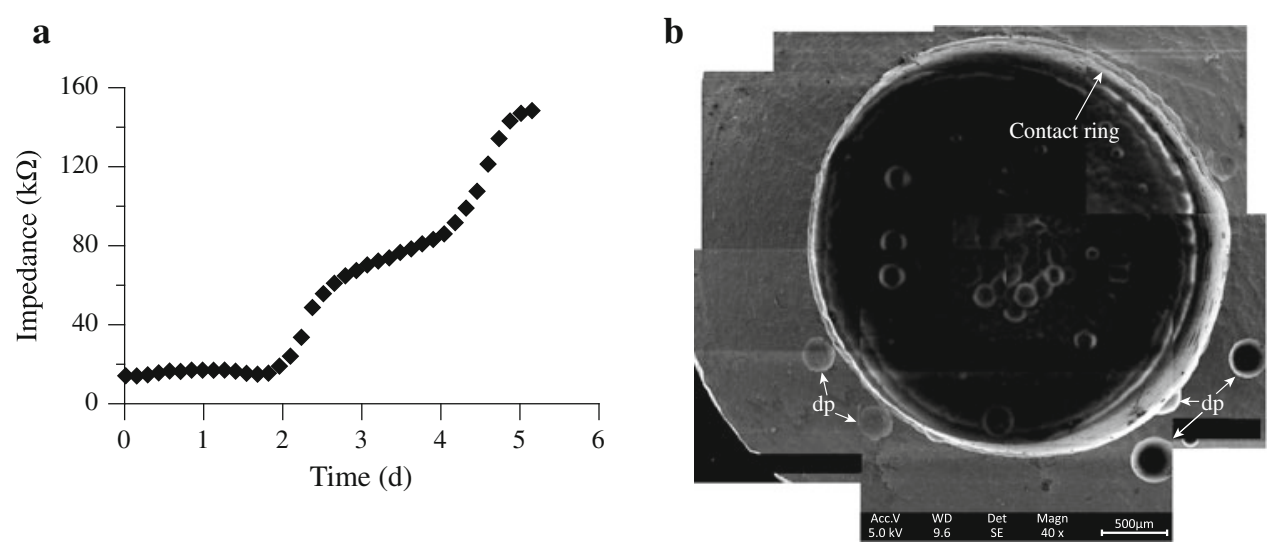

c

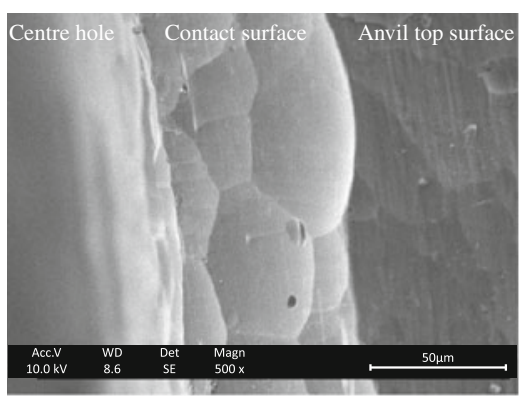

d

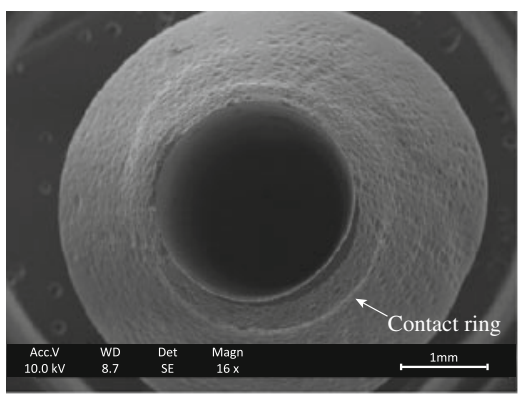

Table 3 Chemical compositions of cell fluids during the experiments

\begin{tabular}{llll}
\hline Element & $\mathrm{GC01}$ & $\mathrm{GC02}$ & $\mathrm{GC03}$ \\
& $\mathrm{C}\left(\mathrm{mol} \mathrm{kg}^{-1}\right)$ & $\mathrm{C}\left(\mathrm{mol} \mathrm{kg}^{-1}\right)$ & $\mathrm{C}\left(\mathrm{mol} \mathrm{kg}^{-1}\right)$ \\
\hline $\mathrm{Si}$ & 0.015 & 0.059 & 0.011 \\
$\mathrm{Ca}$ & 0.00012 & 0.000005 & 0.00071 \\
$\mathrm{Cl}$ & 0.00090 & 0.00028 & 0.00078 \\
$\mathrm{Fe}$ & 0.00005 & 0.000004 & 0.00048 \\
$\mathrm{Ni}$ & 0.00007 & 0.00003 & 0.00001 \\
$\mathrm{~Pb}$ & 0.000005 & 0.000001 & 0.000003 \\
$\mathrm{Zn}$ & 0.00004 & 0.000008 & 0.00002 \\
$\mathrm{Na}$ & - & 0.00004 & 0.00029 \\
$\mathrm{~K}$ & - & 0.00001 & 0.00011 \\
$\mathrm{Al}$ & - & - & 0.000007 \\
$\mathrm{~B}$ & - & - & 0.0017 \\
$\mathrm{Mg}$ & - & - & 0.000008 \\
$\mathrm{Mn}$ & - & - & 0.000008 \\
$\mathrm{~S}$ & - & - & 0.00004 \\
$\mathrm{Sn}$ & - & 0.00004 & - \\
\hline
\end{tabular}

than $\mathrm{H}^{+}$present in the fluid, we can then estimate both the fluid conductivity using Eq. (2), or the value of the sum $\sum D_{i} C_{i} z_{i}^{2}$. The diffusion coefficients of $\mathrm{H}^{+}, \mathrm{OH}^{-}$, $\mathrm{Na}^{+}$and $\mathrm{Cl}^{-}$in bulk water at room temperature are given by Atkins and de Paula (2002) as 9.31, 5.03, 1.33 and $2.03 \times 10^{-9} \mathrm{~m}^{2} \mathrm{~s}^{-1}$, respectively. From these values and assuming an Arrhenius temperature dependence and activation energy of $\sim 15 \mathrm{kJmol}^{-1}$ (Nakashima 1995), diffusion coefficients of $\mathrm{Na}^{+}$and $\mathrm{Cl}^{-}$at experimental conditions (neglecting the effect of pressure) can be estimated as 2.4 and $3.7 \times 10^{-8} \mathrm{~m}^{2} \mathrm{~s}^{-1}$. The diffusion of silica is somewhat slower than the diffusion of alkali metal ions, though still of the same order of magnitude (Nakashima 1995), and the diffusion coefficient of silica is taken here as equal to that of $\mathrm{Na}^{+}$as an upper estimate. The activation energy for the diffusion of $\mathrm{H}^{+}$and $\mathrm{OH}^{-}$was calculated to be $\sim 10 \mathrm{~kJ} / \mathrm{mol}$ from the data of Morash et al. (1994), thus giving values for the diffusion coefficients of $\mathrm{H}^{+}$and $\mathrm{OH}^{-}$at $300^{\circ} \mathrm{C}$ of 6.4 and $3.5 \times 10^{-8} \mathrm{~m}^{2} \mathrm{~s}^{-1}$. Using Eq. (2), the electrical conductivity of the fluid in the tip (assuming bulk diffusivities to be appropriate) is then estimated to be $\sim 0.10 \Omega^{-1} \mathrm{~m}^{-1}$.

Using Eqs. (1) and (2), and the conductivity estimated above, it emerges that the average apparent fluid film thickness, $\delta_{a v}$, was about $\sim 400 \mathrm{~nm}$ in experiment GC01. This is much greater than the values at which surface forces or water structuring effects are expected to reduce diffusion coefficients compared with bulk fluid values (up to $\sim 200 \mathrm{~nm}$ for ice-like structures in water to appear-Nakashima et al. 2001, 2004). Our estimate of $Z=D \delta_{a v} C^{*}$ for the silica glass pressure solution contact then becomes $\sim 6.2 \times 10^{-18} \mathrm{~m}^{3} \mathrm{~s}^{-1}$, assuming that the diffusion coefficient of orthosilicic acid in the grain boundary fluid phase is the same as in bulk water, and assuming that the concentration of silica in the grain boundary fluid phase is equal to the bulk water solubility of amorphous silica. 


\section{Experiment GC02}

In experiment $\mathrm{GC} 02$, the silica glass tube was pressed against a solid silica glass anvil cored from a silica glass plate. The experiment was conducted at a temperature of $353^{\circ} \mathrm{C}$ at the contact, and a fluid pressure of $300 \mathrm{MPa}$. A spring load of $\sim 22 \pm 3 \mathrm{~N}$ was used to load the contact, which resulted in an initial contact normal stress of $\sim 12 \pm 1.5 \mathrm{MPa}$ (calculated from the pre-experimental tip surface area determined from a micrograph). The experiment was stopped after 9 days. As can be seen from Fig. 5a, the total cell resistance remained constant at $\sim 200 \mathrm{k} \Omega$ for approximately 3 days, then increased over the next 4 days to $\sim 1.2 \mathrm{M} \Omega$, then remained constant for another 2 days, at which point the experiment was ended. The starting impedance of the cell at low frequencies was an order of magnitude higher than the other two experiments due to a more thorough cleaning of the cell prior to filling with solution. The experiment also differed by the evolution of a second impedance arc that dominated the final stages. Using a least-squares fitting technique (ZView software from Scribner Associates) with a model for this depressed second arc comprising a constant phase element (CPE) in parallel with a resistance, fitting between the frequencies of $10 \mathrm{kHz}$ and $63 \mathrm{~Hz}$ in the experiment's final state, yielded the following equivalent circuit parameters, seen to be applicable to the dissolution contact. (The complex impedance of the CPE has the form, $Z=A(i \omega)^{-\alpha}$ $(\alpha \leq 1)$ where $1 / A$ is capacitance when $\alpha=1)$. The apparent capacitance of the $\mathrm{CPE}$ was $707.6 \mathrm{pF}( \pm 5.7 \%)$ in parallel with a resistance of $1.1055 \mathrm{M} \Omega( \pm 0.91 \%)$ the arc depression factor $(\alpha)$ was $0.8372( \pm 0.8 \%)$. This is in contrast to the cell capacitance at the start of the experiment of $30.33 \mathrm{pF}( \pm 0.94 \%)$ in parallel with a cell resistance of $167,740 \Omega( \pm 0.55 \%)$ and open dissolution contact. The final apparent capacitance and resistance of the dissolution contact from the second arc data are used later to estimate the local properties of the contact region at its approach to steady evolutionary state (Fig. 3c shows the evolution of the impedance from initially one arc, then two arcs and final approach to steady behaviour during the last 50 measurement runs, with the second arc finally dominating the spectrum).

An image of the tip of the tube after the experiment is shown in Fig. 5b. Post-experimental observation again showed the development of a contact ring, presumably by "pressure dissolution". However, a crack had developed in the tube tip. Also, a small chip was missing from the contact ring on the tip next to the crack. It is unknown whether this damage occurred during the cooling and disassembly stages of the experiment or before heating or measurement. If the crack occurred during the experiment, an observable decrease in contact resistance would be expected, so it seems most likely that the crack occurred while the experiment was being set-up, or during termination. Dissolution on the free surfaces of the silica glass anvil and the silica glass tube was more marked than in experiment GC01, as evidenced by the rugged texture developed on the outer surfaces of the tube and anvil, the conical shape of the initially cylindrical anvil, and an observed decrease rather than increase in contact width. This might have been the result of the higher experimental temperature driving more convection, which in turn, together with faster dissolution kinetics and higher silica solubility, caused increased silica transport rates away from the hot zone. Note that between experiments GC01 and GC02, the set-up was turned upside down, so that the hot spot was now at the top. This was done in order to reduce convection in the system, but had no discernable effect. The image of the tip of the tube (Fig. 5b) shows a contact ring of uneven width (as indicated by the black arrowheads). This variation in width around the ring is caused by the hole in the silica glass tube not being exactly centred.

The composition of the cell fluid after the experiment was again analysed, and the results of the analysis are shown in Table 3 . The very high Si concentration (higher than the silica saturation at $350^{\circ} \mathrm{C}$ ) might be caused by colloidal silica suspended in the fluid, as the fluid looked somewhat milky. From the microscope image (Fig. 5b), the final diameter $(2.4 \mathrm{~mm})$ and average final width $(\sim 83 \mu \mathrm{m})$
Fig. 5 Results from experiment GC02. a Graph showing the evolution of the contact impedance with time. b Optical microscope reflected light image of the contact formed on the glass tip. A $400 \mu \mathrm{m}$ grid is shown over the tip for scale
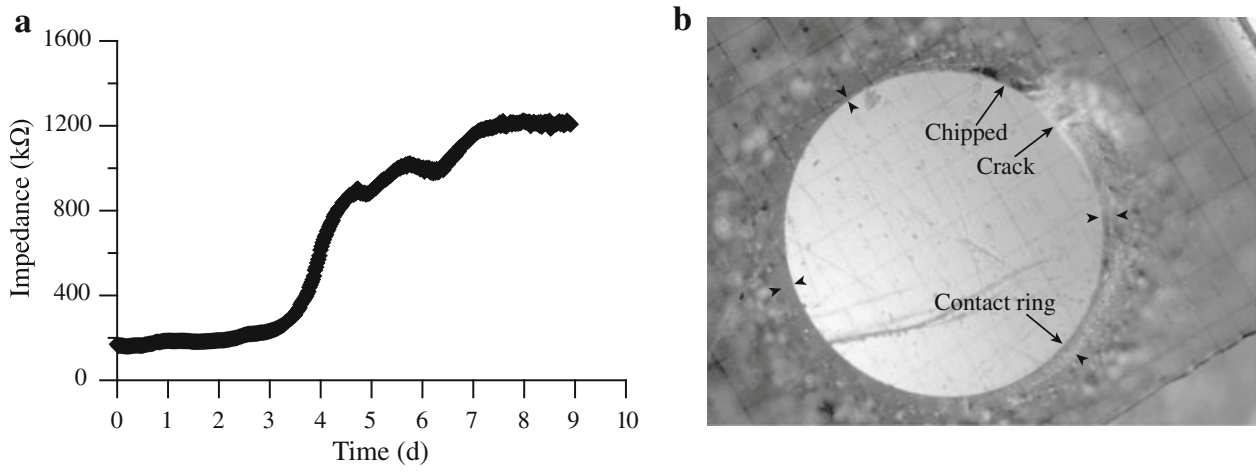
of the contact were determined as before. From this and Eq. (3), we calculated that $\delta_{a v} \sum D_{i} C_{i} z_{i}^{2}=5.00 \times 10^{-15}$ mols ${ }^{-1}$. Furthermore, using the composition of the fluid, and assuming a solution in which all metal cations were monovalent (such as $\mathrm{Na}^{+}$) with a concentration high enough to create charge balance, we can evaluate $\sum D_{i} C_{i} z_{i}^{2}$, to yield an estimate of the conductivity of the fluid around the tip $\left(\sim 0.04 \Omega^{-1} \mathrm{~m}^{-1}\right)$. From the sum $\sum D_{i} C_{i} z_{i}^{2}$, using Eq. (3), we can also estimate that the average fluid film thickness at the end of the experiment was $\sim 230 \mathrm{~nm}$. This results in an estimated value for $Z$ for amorphous silica transport of $\sim 4.9 \times 10^{-18} \mathrm{~m}^{3} \mathrm{~s}^{-1}$.

The interpretation of the second impedance arc, in the final stage of this experiment, leads to an apparent capacitance for the dissolution contact interfacial surfaces of $707.6 \mathrm{pF}$. This would be due to an ionic double layer structure and polarisation of the water-mineral surface as described in Leroy et al. (2008). Apportioning this capacitance to the final contact area would suggest a surface capacitance of $\sim 0.6 \times 10^{-3} \mathrm{Fm}^{-2}$ per separated double layer.

\section{Experiment GC03}

In the final experiment, $\mathrm{GC03}$, the silica glass tube was coated on the outside with a thin platinum layer (sintered platinum paint) to limit dissolution/precipitation. This tube was pressed against a solid crystalline quartz anvil cored from a natural crystal perpendicular to the $\{100\}$ form. The test was performed at a tip temperature of $305^{\circ} \mathrm{C}$ and a fluid pressure of $300 \mathrm{MPa}$, and using a spring load of $\sim 12 \pm 3 \mathrm{~N}$, resulting in an initial contact stress of $\sim 22 \pm 5 \mathrm{MPa}$. As shown in Fig. $6 \mathrm{a}$, the cell resistance decreased from $20 \mathrm{k} \Omega$ to below $10 \mathrm{k} \Omega$ in the first 4 days. After that the resistance steadily increased for 17 days to a maximum contact resistance of $80 \mathrm{k} \Omega$. In the last 6 days of the experiment, the contact resistance continuously decreased to a final value of $67 \mathrm{k} \Omega$, and the experiment was halted after $\sim 27$ days. Due to a large degree of dissolution, transport, precipitation and possibly microcracking, the tube tip was weakened, and only part of the tip could be safely recovered after the experiment. Dissolution (and cracking) lead to undercutting of the platinum painted surface, partly hollowing out the tip of the tube. SEM study of what remains of the contact surface on the tube tip (Fig. 6b) shows some micrometer-scale roughness and some smoother patches. On the quartz anvil (Fig. 6c), the contact surface is visible as a slight depression. Optical analysis indicated that some dissolution took place on this contact surface, but subsequent precipitation cannot be excluded. The contact surface on the quartz anvil also shows roughness with a lateral length scale of a few

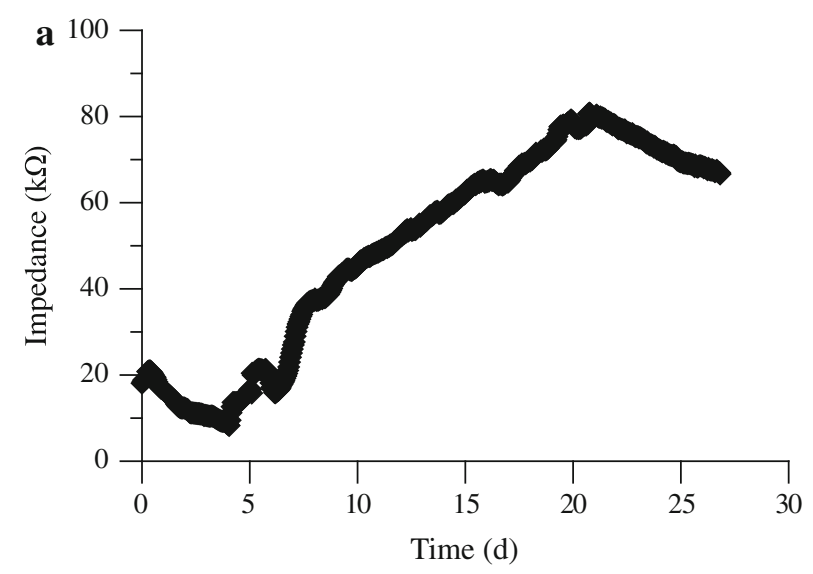

b
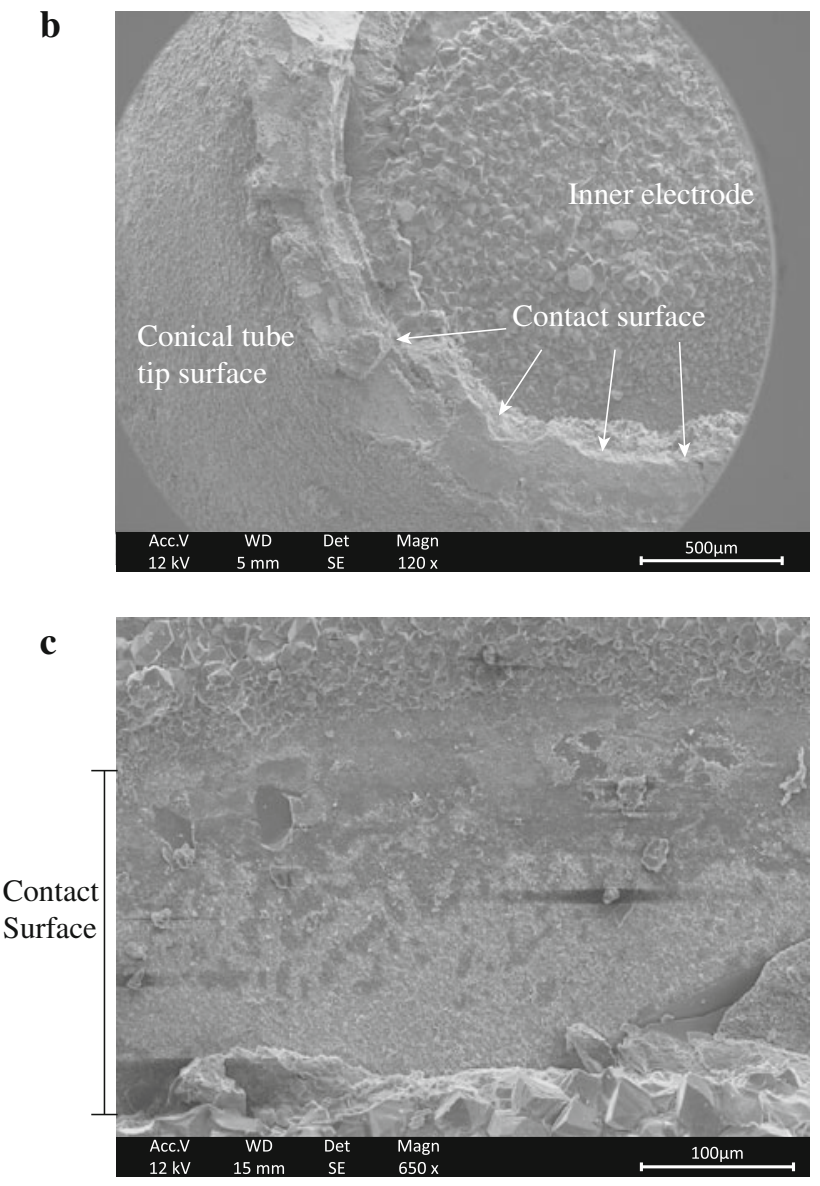

Fig. 6 Results from experiment GC03. a Graph showing the evolution of the contact impedance with time. b SEM SE image of part of the contact ring on the glass tube tip. Note also the silica precipitated on part of the inner electrode. c Close-up SEM SE image of the contact ring on the quartz anvil

micrometers, and with sub-micrometer scale amplitude. The rough texture on both the tip and the anvil contact surfaces is much finer than, and does not show the reniform appearance of the roughness observed on the contact in experiment GC01. Unfortunately, it cannot be determined 
with certainty whether these textures represent dissolution or precipitation features.

An estimate of the contact width $(\sim 95 \mu \mathrm{m})$ and diameter $(\sim 2.3 \mathrm{~mm})$ was made for GC03 from the SEM micrographs, assuming that a contact with even width existed during the experiment. These values, coupled with Eq. (3) then give: $\delta_{a v} \sum D_{i} C_{i} z_{i}^{2}=1.01 \times 10^{-13} \mathrm{mols}^{-1}$. In combination with the fluid composition analysis (Table 3), and again simplifying the fluid conductivity calculation by assuming that all charge from contaminant ions is carried by $\mathrm{Na}^{+}$and $\mathrm{Cl}^{-}$(resulting in a value of $\kappa \approx 0.40 \Omega^{-1} \mathrm{~m}^{-1}$ ), estimates of the average grain boundary fluid film thickness and of the grain boundary diffusivity product $(Z)$ for amorphous silica transport were made. The values obtained are $500 \mathrm{~nm}$ and $\sim 7.7 \times$ $10^{-18} \mathrm{~m}^{3} \mathrm{~s}^{-1}$, respectively. However, since only part of the tube tip could be recovered intact after the experiment, we cannot be certain that a completely closed contact ring had formed. Moreover, as seen in Fig. 6b, during this experiment a large amount of precipitation of silica occurred, also on part of the disc-surface of the inner electrode. This might have been a cause for the observed increase in cell resistance, rather than closure of the contact. Such an effect should not become a problem, however, until the surface area of the (inner) disc-electrode available for conduction becomes similar to the cross-sectional area of the fluid pathway between the tube and anvil, which is $>3$ orders of magnitude smaller. It is not expected that silica precipitation on the electrode influenced our measurements in this experiment.

\section{Synthesis}

Our three experiments have yielded estimates of the average fluid film thickness $\left(\delta_{\text {av }}\right)$ in silica-glass/silica-glass or silica-glass/quartz contacts undergoing pressure solution, between 230 and $500 \mathrm{~nm}$, and estimates for the silica diffusivity product $\left(Z=D \delta_{\mathrm{av}} C^{*}\right)$ for these contacts between $4.9 \times 10^{-18}$ and $7.7 \times 10^{-18} \mathrm{~m}^{3} \mathrm{~s}^{-1}$, assuming there are no thin film effects on diffusivity (i.e., assuming diffusivities in bulk water), and assuming that the electrical resistance measured resulted from ionic conduction through a bulk fluid phase in the contacts. This latter assumption requires further discussion, as room temperature electrical conductivity measurements through granular porous media, such as packs of beads, have shown surface conduction at the water-mineral interface to be dominant (e.g., Leroy et al. 2008). As discussed by Revil and Glover (1998), for quartz-water interfaces, excess conduction through the Stern layer is the main contribution to the specific surface conductance. The excess conductance of the Stern layer at $T=300$ or $350^{\circ} \mathrm{C}$, and for fluid compositions relevant to our experiments can be calculated using the equation given by Revil and Glover (1998 - their equation 9):

$\Sigma_{\mathrm{S}}^{\mathrm{Stern}}=e \beta_{\mathrm{S}} \Omega_{M}^{0} \Gamma_{\mathrm{S}}^{0}$

where $e$ is the elementary charge $\left(1.6 \times 10^{-19} \mathrm{C}\right), \beta_{\mathrm{S}}$ is the equivalent mobility of the adsorbed ions in the Stern layer (roughly 0.1 times the ionic mobility in bulk fluid-e.g., Revil and Glover 1998), $\Gamma_{\mathrm{S}}^{0}$ is the total surface site density (4.6 $\mathrm{nm}^{-2}$ according to Hiemstra and Van Riemsdijk 1990), and $\Omega_{M}^{0}$ is the relative surface density of adsorbed ions, given by Revil and Glover (1998) as:

$\Omega_{M}^{0}=\frac{K_{M} C_{\mathrm{f}}}{10^{-\mathrm{pH}}+K_{(-)}+K_{M} C_{\mathrm{f}}}$.

Here, $C_{\mathrm{f}}$ is the fluid salinity $\left(\mathrm{mol} \mathrm{l}^{-1}\right)$ and $K_{(-)}$and $K_{M}$ are the equilibrium constants of, respectively, the reactions:

$$
\begin{aligned}
& >\mathrm{SiOH} \Leftrightarrow>\mathrm{SiO}^{-}+\mathrm{H}^{+} \\
& >\mathrm{SiOH}+\mathrm{M}^{+} \Leftrightarrow>\mathrm{SiOM}+\mathrm{H}^{+} .
\end{aligned}
$$

Applying the above equation for the Stern layer conductance to our experimental conditions, and contact geometries, shows that for experiments GC01 and GC03, surface conduction is limited compared to conduction through the bulk fluid, with the resistance of each Stern layer being about one order of magnitude larger than the total measured contact resistance. For experiment GC02, it shows that the excess conduction through the Stern layer had a resistance roughly $5 \times$ higher than the total measured contact resistance, implying that, assuming parallel conduction through the two Stern layers and the bulk fluid in the contact, the actual contact width may have been $140 \mathrm{~nm}$. Therefore, while conduction through the surface layers was neglected in our calculations, the resulting estimates for the average fluid film thickness $\delta_{\mathrm{av}}$ are not strongly affected by this, with the resulting errors being less than a factor $\sim 2$.

Despite irregularities, such as cracks or voids, in our contacts influencing our estimates for $\delta_{\mathrm{av}}$, these estimates are similar to the contact surface roughness observed in some of our dissolved contact rings (Fig. 4c). However, they are much higher than the values of $\sim 0-5 \mathrm{~nm}$ for fluid films between smooth silicate surfaces, determined at room temperature using the surface forces apparatus (e.g., Vigil et al. 1994; Alcantar et al. 2003). This is perhaps not surprising since little or no surface dissolution is expected during surface forces experiments performed at room temperature. Higher values for $\delta_{\mathrm{av}}$ in the range 1-100 nm have been estimated from post-experimental observations on granular quartz compacted by pressure solution (Cox and Paterson 1991), from comparisons of experimental pressure solution rates with theoretical models (e.g., Gratier and Guiguet 1986) and from a model of a 
Debye-Hückel double layer combined with osmotic pressure (Renard and Ortoleva 1997). These values are still lower than the values reported here, though. As a result of our high mean fluid film thickness and assumed bulk diffusion coefficients, our estimated values for $D \delta_{\mathrm{av}}$ (and therefore $Z$ ) are between a half and four orders of magnitude higher than generally derived in quartz pressure solution models that assume diffusion to be rate-limiting (Gratier and Guiguet 1986; Shimizu 1995; Revil 2001; Revil et al. 2006).

The most likely cause for our high $\delta_{\text {av }}$ estimates is the rough contact structure with an additional, possibly major, effect of incomplete "closure" of the contacts due to larger scale cracking and pitting. In experiment GC01, for example, the dissolution pit intersecting the contact ring (Fig. 4b) might have formed a fast pathway for conduction. The non-uniform contact width also made estimates of the average width $(w)$ of the contact difficult, as most conduction would occur through the narrow part of the contact ring, though such effects are unlikely to yield order of magnitude errors. Likewise, the possibility of microcracking and a non-uniform contact width may have influenced our results in experiments $\mathrm{GC} 02$ and $\mathrm{GC} 03$.

As already mentioned, our SEM studies indicate that our (pressure dissolving) silica contacts were rough. The scale of the rough texture varies between experiments GC01 and GC03 from reniform depressions of up to $100 \times 50 \mu \mathrm{m}$ and up to $\sim 5 \mu \mathrm{m}$ deep, to a rough network of islands on a micrometer-scale, with sub-micrometer scale amplitude. Note, though, that the structure observed on GC03 might have resulted from precipitation rather than dissolution. An island and channel texture on pressure dissolving quartz grain boundaries has previously been reported by Cox and Paterson (1991) and Den Brok (1998). Examining their results in more detail, Cox and Paterson (1991) report an irregular network of ridges and channels with a lateral length scale of $0.05-3 \mu \mathrm{m}$ developed on a quartz contact that underwent pressure solution at $927^{\circ} \mathrm{C}, 200 \mathrm{MPa}$ fluid pressure and $300 \mathrm{MPa}$ confining pressure. Den Brok (1998) shows a pressure solution contact from a quartzite with a similar island-channel grain boundary structure, but which is slightly coarser $(0.5-5 \mu \mathrm{m})$ and in which the channels are deeper and interpreted as cracks. Rough pressure dissolving contacts were thus reported in both of these studies and were observed in our work (in experiment GC01, and possibly in experiment GC03). However, the scale and morphology of the island-channel networks reported by Cox and Paterson (1991) and Den Brok (1998) are different from the scale and morphology observed here, especially compared with the reniform structures seen in GC01. Furthermore, Cox and Paterson (1991) estimate the roughness to have an amplitude of up to $100 \mathrm{~nm}$, which is of the same order as, though still smaller than, the grain boundary fluid film thicknesses estimated here. This strengthens our belief that our data overestimate grain boundary film thicknesses. Though larger scale cracking might have occurred in some of our experiments (most notably GC02), the contact structures observed here did not appear to be related to cracking normal to the contact as described by Den Brok (1998).

In contrast to the above reports, Dewers and Hajash (1995) show SEM images of contacts on grains that underwent pressure solution at only $150^{\circ} \mathrm{C}$. Their betterdeveloped contacts are quite flat (especially compared to their free faces) but do show some pits on the scale of a few micrometers. Their observations, thus, are quite different from the rough contact structures reported here and by Cox and Paterson (1991) and Den Brok (1998).

Drawing the above information together, the rough structures observed on our dissolving contacts, and the associated cracking, support previous inferences and model calculations (Gratz 1991; Schutjens 1991; Dewers and Hajash 1995; Renard et al. 1999; Niemeijer et al. 2002) that diffusion during pressure solution in quartz grain boundaries is likely to be very fast. Our results thus support the notion that, during quartz pressure solution, interface kinetics, i.e., either dissolution or precipitation, are probably the rate-limiting process.

\section{Future experiments}

As discussed above, our experiments did not result in accurate estimates of $\delta_{\mathrm{av}}$ and $Z$, as several unsolved problems probably prevented a continuous, uniformly structured contact from forming. A challenging problem was convection driven silica dissolution and transport from the contact area. Precipitation patterns, and the amount of precipitation, demonstrated for instance by the silica glass tube getting stuck inside the platinum outer tube in some experiments show that convection driven transport is a factor in our experiments. It is also a possible factor affecting contact formation. Post-experimental observations did show that the precipitation-free electrode surface area remained much larger than the estimated tube tip window through which conduction took place, indicating that precipitation on the electrodes did not cause the observed increases in impedance in our experiments, with possible exception of GC03. Several attempts to reduce convection, such as inverting the cell (from tip-down to tipup), reducing the amount of fluid in the cell by including platinum spacers, blocking convection with a platinum skirt and preventing dissolution with a coating of platinum on the silica tube met with only limited success. The convection problem thus needs a better solution for future experiments. Another factor was cracking. Though room temperature and atmospheric pressure tests showed no 
cracking at contact stresses higher than those used here, cracking still seemed to be an issue, especially in experiments GC02 and GC03. Finally, it was unfortunately not possible to accurately calculate the changes in contact load during heating and pressurisation. Using a spring with a lower spring constant would mean that differences in thermal expansion of the vessel and cell would influence the applied load less and would result in a more constant and more reliably estimated load throughout the experiment.

\section{Conclusions}

In an attempt to investigate the structure and diffusive properties of grain boundaries in silicate materials during pressure solution, we performed experiments in which a silica glass tube was pressed against a silica glass or quartz single-crystal anvil under hydrothermal conditions. Impedance spectroscopy was used to monitor the electrical impedance and hence diffusive properties of the contact. In many experiments, a continuous contact did not form, but we report the results of three experiments in which a reasonably continuous pressure solution contact was produced. Post-experimental optical microscopy and SEM study was used to determine the diameter, width and surface texture of the contact rings that formed in these three moderately successful experiments. After each experiment, the chemical composition of the fluids in the experimental cell was determined by mass spectroscopy. Using this composition, plus calculations of the concentrations of $\mathrm{H}^{+}$, $\mathrm{OH}^{-}, \mathrm{H}_{3} \mathrm{SiO}_{4}{ }^{-}$and $\mathrm{H}_{2} \mathrm{SiO}_{4}{ }^{2-}$ present in the fluids in our cell at experimental conditions, the conductivity of the fluids in the contact was estimated (through the NernstEinstein equation). From this, the mean contact width $\left(\delta_{\mathrm{av}}\right)$ and grain boundary diffusivity product $(Z)$ for quartz pressure solution were estimated.

In the three experiments reported here, we found an average grain boundary fluid film thickness of $\sim 140$ $500 \mathrm{~nm}$, which is one to two orders of magnitude higher than generally assumed for quartz grain boundaries during pressure solution. This is similar to the internal grain boundary roughness observed post-mortem in some of our tests. From this thickness, relatively high values for the silica grain boundary diffusivity product $Z=D \delta_{\text {av }} C^{*}$ were estimated in the range $4.9-7.7 \times 10^{-18} \mathrm{~m}^{3} \mathrm{~s}^{-1}$. Though considerable roughness was observed within the dissolved contacts, our estimates for the grain boundary fluid film thickness, and the grain boundary diffusivity product, are likely too high due to non-uniform development of our contacts related to microcracking and/or irregular dissolution pitting.
Rough contact structures, though with a different morphology than the contact structures observed in some of the present experiments, were reported previously by both Cox and Paterson (1991) and Den Brok (1998) for grain boundaries in granular quartz aggregates compacted by pressure solution. Cox and Paterson estimated an amplitude on the order of up to $100 \mathrm{~nm}$ for this roughness, which is smaller than our estimates of the average contact fluid film thickness. Taking into account the roughness observed in our contacts, and the tendency for microcracking and irregular dissolution, our results support earlier predictions and conclusions (e.g., Renard et al. 1999; Dewers and Hajash 1995; Niemeijer et al. 2002) that during pressure solution diffusion through quartz grain boundaries is likely to be relatively fast, especially where cracks and other irregularities provide fast diffusion pathways short-circuiting the thin film. Our results accordingly point to quartz pressure solution being interface reaction controlled (dissolution or precipitation controlled), at least under hydrothermal conditions.

Acknowledgments This research and the position of RvN were funded by the Netherlands Organisation for Scientific Research, grant number 814.01.001. The authors would like to thank Eimert de Graaff for his outstanding technical support, Peter van Krieken for his help with the SEM, and André Revil for his helpful review of the original manuscript.

Open Access This article is distributed under the terms of the Creative Commons Attribution Noncommercial License which permits any noncommercial use, distribution, and reproduction in any medium, provided the original author(s) and source are credited.

\section{References}

Alcantar N, Israelachvili J, Boles J (2003) Forces and ionic transport between mica surfaces: implications for pressure solution. Geochim Cosmochim Acta 67:1289-1304

Atkins P, de Paula J (2002) Atkins' physical chemistry, 7th edn. Oxford University Press Inc., New York

Barsoukov E, Macdonald JR (eds) (2005) Impedance spectroscopy theory, experiment, and applications, 2nd edn. Wiley, Hoboken, p 595

Bolève A, Crespy A, Revil A, Janod F, Mattiuzzo JL (2007) Streaming potentials of granular media: Influence of Dukhin and Reynolds numbers. J Geophys Res 112:B08204. doi:10.1029/ 2006JB004673

Cox SF, Paterson MS (1991) Experimental dissolution-precipitation creep in quartz aggregates at high temperatures. Geoph Res Lett 18:1401-1404

De Meer S, Spiers CJ, Peach CJ, Watanabe T (2002) Diffusive properties of fluid-filled grain boundaries measured electrically during active pressure solution. Earth Planet Sc Lett 200:147157

De Meer S, Spiers CJ, Nakashima S (2005) Structure and diffusive properties of fluid-filled grain boundaries: an in situ study using Infrared (micro) spectroscopy. Earth Planet Sc Lett 232:403-414 
Den Brok B (1998) Effect of microcracking on pressure-solution strain rate: the Gratz grain-boundary model. Geology 26:915918

Dewers TA, Hajash A (1995) Rate laws for water-assisted compaction and stress-induced water-rock interaction in sandstones. J Geophys Res 100(B7):13093-13112

Gratier JP, Guiguet R (1986) Experimental pressure solution-deposition on quartz grains: the crucial effect of the nature of the fluid. J Struct Geol 8:845-856

Gratier JP, Guiguet R, Renard F, Jenatton L (2006) Experimental pressure solution creep of quartz by indenter technique, AGU Fall Meeting 2006, San Francisco

Gratz AJ (1991) Solution-transfer compaction of quartzites: progress toward a rate law. Geology 19:901-904

Gunnarsson I, Arnórsson S (2000) Amorphous silica solubility and the thermodynamic properties of $\mathrm{H}_{4} \mathrm{SiO}_{4}$ in the range of $0^{\circ}$ to $350^{\circ} \mathrm{C}$ at $\mathrm{P}_{\text {sat }}$. Geochim Cosmochim Acta 64(13):2295-2307

Hickman SH, Beeler NM (1997) Direct measurements of diffusive contact growth in quartz at hydrothermal conditions, with implications for interseismic strength recovery. AGU 1997 Fall Meeting, San Francisco

Hickman SH, Evans B (1991) Experimental pressure solution in halite: the effect of grain/interphase boundary structure. J Geol Soc Lond 148:549-560

Hickman SH, Evans B (1992) Growth of grain contacts in halite by solution-transfer: implications for diagenesis, lithification, and strength recovery. In: Evans B, Wong TF (eds) Fault mechanics and transport properties of rocks. Academic Press, San Diego, pp 253-280

Hickman SH, Evans B (1995) Kinetics of pressure solution at halitesilica interfaces and intergranular clay films. J Geoph Res 100(B7):13113-13132

Hiemstra T, Van Riemsdijk WH (1990) Multiple activated complex dissolution of metal (hydr)oxides: a thermodynamic approach applied to quartz. J Colloid Interf Sci 136(1):132-150

Horn RG, Smith DT, Haller W (1989) Surface forces and viscosity of water measured between silica sheets. Chem Phys Lett 162(4-5):404-408

International Association for the Properties of Water and Steam (1980) Release on the ion product of water substance May 1980, available from http://www.iapws.org

Israelachvili J (1986) Measurement of the viscosity of liquids in very thin films. J Colloid Interf Sci 110(1):263-271

Lehner FK (1990) Thermodynamics of rock deformation by pressure solution. In: Barber DJ, Meredith PG (eds) Deformation processes in minerals, ceramics and rocks. Unwin Hyman, London, pp 296-333

Lehner FK (1995) A model for intergranular pressure solution in open systems. Tectonophysics 245:153-170

Leroy P, Revil A, Kemna A, Cosenza P, Ghorbani A (2008) Complex conductivity of water-saturated packs of glass beads. J Colloid Interf Sci 321(1):103-117

Morash KR, Thornton RD, Saunders CH, Bevilacqua AC (1994) Measurement of the resistivity of ultrapure water at elevated temperatures. Ultrapure Water 11(9):18-26

Nakashima S (1995) Diffusivity of ions in pore water as a quantitative basis for rock deformation rate estimates. Tectonophysics 245(3-4):185-203

Nakashima S, De Meer S, Spiers CJ, Famin V, Hirono T (2001) Physiochemical properties of water in grain boundaries"Hard" water in the deep crust and the origin of earthquake? In: Proceedings of international symposium on slip \& flow processes in and below the Seismogenic Region, Nov 5-7, 2001, Sendai, Japan

Nakashima S, De Meer S, Spiers CJ (2004) Distribution of thin film water in grain boundaries of crustal rocks and implications for crustal strength. In: Nakashima S, Spiers CJ, Mercury L, Fenter PA, Hochella MF Jr (eds) Physicochemistry of water in geological and biological systems - structures and properties of thin aqueous films. Universal Academy Press, Tokyo, pp 159-178

Niemeijer AR, Spiers CJ, Bos B (2002) Compaction creep of quartz sand at 400-600 degrees C; experimental evidence for dissolution-controlled pressure solution. Earth Planet Sci Lett 195:261-275

Renard F, Ortoleva P (1997) Water at grain-grain contacts: DebyeHückel, osmotic model of stress, salinity, and mineralogy dependence. Geochim Cosmochim Ac 61:1963-1970

Renard F, Ortoleva P, Gratier JP (1997) Pressure solution in sandstones: influence of clays and dependence on temperature and stress. Tectonophysics 280:257-266

Renard F, Park A, Ortoleva P, Gratier JP (1999) An integrated model for transitional pressure solution in sandstones. Tectonophysics 312:97-115

Revil A (2001) Pervasive pressure solution transfer in a quartz sand. J Geoph Res 106(B5):8665-8686

Revil A, Glover PWJ (1997) Theory of ionic-surface electrical conduction in porous media. Phys Rev B 55(3):1757-1773

Revil A, Glover PWJ (1998) Nature of surface electrical conductivity in natural sands, sandstones, and clays. Geophys Res Lett 25(5):691-694

Revil A, Pezard PA, Glover PWJ (1999) Streaming potential in porous media 1 . Theory of the zeta potential. J Geophys Res 104(B9):20021-20031

Revil A, Leroy P, Ghorbani A, Florsch N, Niemeijer AR (2006) Compaction of quartz sands by pressure solution using a ColeCole distribution of relaxation times J Geophys Res 111:B09205, doi:10.1029/2005JB004151

Rimstidt JD (1997) Quartz solubility at low temperatures. Geochim Cosmochim Acta 61(13):2553-2558

Rutter EH (1976) The kinetics of rock deformation by pressure solution. Philos Trans R Soc A 283:203-219

Rutter EH (1983) Pressure solution in nature, theory and experiment. J Geol Soc Lond 140:725-740

Schutjens PMTM (1991) Experimental compaction of quartz sand at low effective stress and temperature conditions. J Geol Soc Lond 148:527-539

Schutjens PMTM, Spiers CJ (1999) Intergranular pressure solution in $\mathrm{NaCl}$ : grain-to-grain contact experiments under the optical microscope. Oil Gas Sci Technol 54:729-750

Shimizu I (1995) Kinetics of pressure solution creep in quartz: theoretical considerations. Tectonophysics 245:121-134

Spiers CJ, Schutjens PMTM, Brzesowsky RH, Peach CJ, Liezenberg JL, Zwart HJ (1990) Experimental determination of constitutive parameters governing creep of rocksalt by pressure solution. In: Knipe RJ, Rutter EH (eds) Deformation mechanisms, rheology and tectonics, Geological Society of London Special Publications, vol 54, pp 215-227

Van Noort R, Spiers CJ, Peach CJ (2006) Effects of orientation on the diffusive properties of fluid-filled grain boundaries during pressure solution. Phys Chem Miner 34(2), doi:10.1007/s00269006-0131-9

Van Noort R, Visser HJM, Spiers CJ (2008) Influence of grain boundary structure on dissolution controlled pressure solution and retarding effects of grain boundary healing. J Geophys Res 113:B03201. doi:10.1029/2007JB005223

Vigil G, Xu Z, Steinberg S, Israelachvili J (1994) Interactions of silica surfaces. J Colloid Interf Sci 165:367-385

Visser HJM (1999) Mass transfer processes in crystalline aggregates containing a fluid phase. Ph. D. thesis, Utrecht University, Utrecht

Volosov AG, Khodakovskiy IL, Ryzhenko BN (1972) Equilibria in the system $\mathrm{SiO} 2-\mathrm{H} 2 \mathrm{O}$ at elevated temperatures along the lower three-phase curve. Geochem Int 9:362-377 
Watanabe T, Peach CJ (2002) Electrical impedance measurement of plastically deforming halite rocks at $125^{\circ} \mathrm{C}$ and $50 \mathrm{MPa}$. J Geophys Res 107(B1), 2004, doi:10.1029/2001JB000204

Zhang X, Spiers CJ (2005) Compaction of granular calcite by pressure solution at room temperature and effects of pore fluid chemistry. Int J Rock Mech Mining Sci 42:950-960

Zhang X, Salemans J, Peach CJ, Spiers CJ (2002) Compaction experiments on wet calcite powder at room temperature:
Evidence for operation of intergranular pressure solution. In: De Meer S, Drury MR, De Bresser JHP, Pennock GM (eds) Deformation mechanisms, rheology and tectonics: current status and future perspectives. Geological Society Special Publications 200, London, pp 73-83

Zubtsov S, Renard F, Gratier JP, Guiguet R, Dysthe DK, Traskine V (2004) Experimental pressure solution compaction of synthetic halite/calcite aggregates. Tectonophysics 385:45-57 